\title{
Crescimento, produção e qualidade de frutos de tomateiro em cultivo adensado com uso de paclobutrazol
}

\section{Growth, yield and quality of tomato fruits in narrow cultivation with the use of paclobutrazol}

NOZIMARY CARNEIRO FERREIRA'

EDUARDO PRADI VENDRUSCOLO $0^{1,4}$

ALEXSANDER SELEGUINI ${ }^{2}$

WILSON DE SOUZA DOURADO'

CLEITON GREDSON SABIN BENETT ${ }^{3}$

ABADIA DOS REIS NASCIMENTO'

Cultivo de tomate em Anápolis, Goiás (Brasil).

Foto: N.C. Ferreira

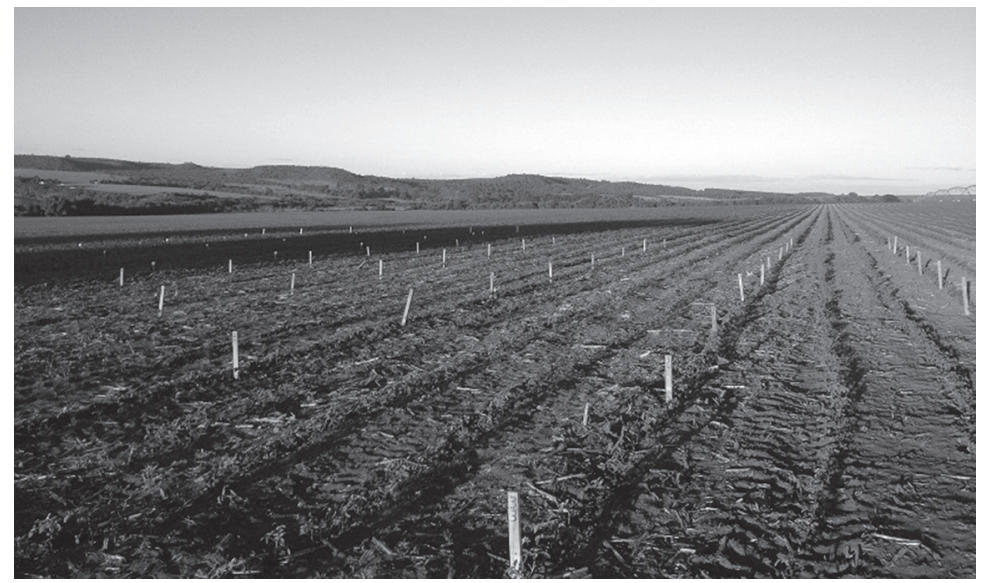

\section{RESUMEN}

O estudo teve como objetivo avaliar o efeito da aplicação do regulador de crescimento paclobutrazol nas mudas e do espaçamento entre plantas na linha de plantio do tomate industrial. O experimento foi conduzido de julho a outubro de 2013 em Anápolis, GO. Utilizou-se o delineamento em blocos casualizados, em esquema fatorial de $5 \times 2$ (espaçamento $\times$ presença ou ausência de paclobutrazol). Foram determinados o comprimento da haste principal e diâmetro médio do caule das plantas, teor de clorofila nas folhas, produção total ( $\left(\mathrm{h}^{-1}\right)$, número médio de frutos e massa fresca de frutos, distribuição dos frutos em maduro, verde e deteriorados, número de frutos maduro e verde, massa média de frutos maduro e verde, teores de sólidos solúveis, acidez titulável, pH, relação SS/AT, porcentagem de compressão e força máxima para rompimento da epiderme e resíduo de paclobutrazol nos frutos. Os resultados mostraram que a aplicação de paclobutrazol influencia até os 15 após o transplantio o comprimento das hastes e o teor de clorofila nas folhas, mostrando que o efeito do regulador é limitado durante o ciclo da cultura, não influenciando sobre os parâmetros de produção do tomate industrial. A aplicação de PBZ não influenciou em nenhum dos parâmetros de qualidade química e física avaliados. As densidades de plantio estudadas não alteraram os componentes de produção e qualidade de frutos do tomateiro. Não foram detectados resíduos de paclobutrazol em frutos de tomateiro para processamento industrial que receberam a aplicação do regulador nas mudas.

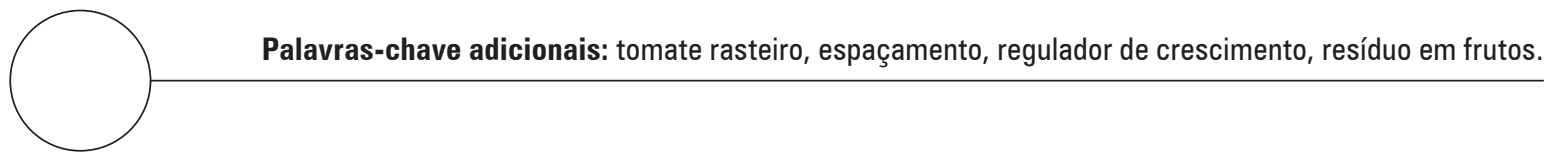

\footnotetext{
Escola de Agronomia, Universidade Federal de Goiás (EA/UFG), Goiânia, Goiás (Brasil).

2 Campus de Iturama, Universidade Federal do Triângulo Mineiro (UFTM), Iturama, Minas Gerais (Brasil).

3 Campus de Ipameri, Universidade Estadual de Goiás (UEG), Ipameri, Goiás (Brasil).

4 Autor para correspondência. agrovendruscolo@gmail.com
} 


\section{ABSTRACT}

The aim of the study was to evaluate the effect of applying a paclobutrazol growth regulator on plants and plant spacing in the planting lines of industrial tomatoes was evaluated. The experiment was conducted from July to October. A randomized block strategy in a $5 \times 2$ factorial design (spacing $x$ presence or absence of paclobutrazol) was used. The length of the main stem and stem diameter of the plants, chlorophyll content in leaves, total production $\left(t \mathrm{t}^{-1}\right)$, average number of fruits and fresh fruit weight, distribution of ripe, unripe and rotten fruits, number of ripe and unripe fruits, average weight of ripe and unripe fruits, soluble solids content, titratable acidity, pH, SS/TA ratio, percentage of compression and maximum strength to break and paclobutrazol residue in fruits were all determined. The results showed that Paclobutrazol influences the length of rods and chlorophyll content in leaves up to 15 days after transplanting, showing that the effect of the regulator is limited during the culture cycle. And, the regulator did not influence the production parameters of the industrial tomatoes. The application of PBZ did not influence any of the chemical or physical quality parameters that were evaluated. The plant densities studied did not alter the production and fruit quality components of the tomato. No residues of paclobutrazol were detected in tomato fruits for industrial processing that received an application of the regulator in the seedlings.

Additional key words: creeping tomato, spacing, growth regulator, fruit residue.

Data de recepção: 20-12-2016 Aprovado para publicação: 15-04-2017

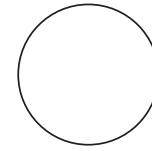

A cultura do tomateiro destaca-se, mundialmente, por sua importância econômica e social e sua versatilidade, podendo ser consumido cru ou processado (Fontes e Silva, 2005). A safra de tomate industrial estimada para o Estado de Goiás em 2014 foi de aproximadamente 1,1 milhão de toneladas, numa área plantada de 14.500 ha, com uma produtividade média de $80 \mathrm{t} \mathrm{ha}^{-1}$ de frutos. $O$ estado tem uma participação de aproximadamente $65 \%$ de todo o tomate industrial plantado no Brasil. Já a safra brasileira de tomate industrial é estimada em mais de 1,9 milhão de toneladas em 2014. Este número o coloca como o sétimo maior produtor de tomate para processamento no mundo (Rabelo, 2014).

A agroindústria necessita de um tipo especial de frutos, produzido em cultura rasteira, sem tratos culturais sofisticados, e reduzido custo de produção. Os frutos precisam apresentar alta resistência ao transporte a granel, coloração vermelha intensa e uniforme, elevado teor de sólidos solúveis e teor de ácido cítrico. A sustentabilidade econômica das indústrias de processamento de tomate depende da qualidade da matéria-prima, que determina, em grande parte, a qualidade do produto final (Schwarz et al., 2013).

O espaçamento de plantio é um dos principais itens na cadeia de técnicas de cultivo de tomate, interferindo no ciclo da planta, dificultando o controle de doenças e diminuindo a qualidade dos frutos colhidos (Fery e Janick, 1970; Nichols, 1987). Em complemento, a técnica pode trazer como consequência o estiolamento do caule devido ao aumento do comprimento de internódios (Adpawar et al., 2000), não influindo sobre o número de frutos por planta, mas sim, sobre a massa média dos frutos (Seleguini et al., 2002, Carvalho e Tessarioli Neto, 2005). Buscam-se alternativas que possibilitem a maior produção, mantendo-se a qualidade dos frutos.

A utilização de reguladores vegetais consta como uma prática viável à supressão das demandas produtivas. Dentre os produtos utilizados, o paclobutrazol (PBZ) tem surtido efeitos de interesse em plantas de tomateiro, nas quais reduz a altura, aumenta a espessura do talo de plantas jovens e acelera a formação de raiz (Berova e Zlatev, 2000). Os efeitos são ocasionados pelo bloqueio da biossíntese do ácido giberélico, diminuindo o desenvolvimento vegetal, evitando a sobreposição de ramos durante o ciclo produtivo e, consequentemente melhorando as condições de cultivo em um sistema adensado.

Diante do exposto, objetivou-se avaliar o crescimento de plantas tratadas com PBZ em diferentes densidades de plantio, bem como suas influências nos componentes de produção e produtividade do tomateiro para o processamento industrial. 


\section{MATERIAL E MÉTODOS}

O experimento foi conduzido em propriedade de plantio comercial de tomate para o processamento industrial localizada no município de Anápolis, Goiás. O local está localizado na latitude 48 $18^{\prime} 23^{\prime \prime}$ W e longitude $16^{\circ} 19^{\prime} 44^{\prime \prime} \mathrm{S}$, à altitude de $1.017 \mathrm{~m}$. O solo da área foi classificado como Latossolo Vermelho-Escuro eutrófico de textura argilosa. Os resultados da análise química do solo estão apresentados na tabela 1.

O clima do local, segundo a classificação climática, é o Aw, caracterizado como mesoclimático, regime pluviométrico tropical semi-úmido com estação seca bem definida e regime térmico quente (Nimer, 1979), com temperatura média anual de $22^{\circ} \mathrm{C}$ e precipitação de $1.610 \mathrm{~mm}$.

O híbrido utilizado foi o N901, para o processamento industrial, de ciclo intermediário (115-120 d), com massa média entre 70-80 g, coloração vermelha intensa, sólidos solúveis elevados e alta resistência às doenças, como murcha de verticílio, murcha de fusário e pinta bacteriana, e resistência intermediária a nematoides (Nunhems, 2014).

Adotou-se o delineamento experimental em blocos casualizados em esquema fatorial $2 \times 5$ (presença ou ausência de paclobutrazol nas mudas $\times$ espaçamentos entre plantas na linha), com quatro repetições. Cada parcela foi composta por quatro linhas de plantio do híbrido N901, com 3,5 m de comprimento, totalizando uma área total de $14 \mathrm{~m}^{2}$. Utilizaram-se como área útil das parcelas as duas linhas centrais, desprezandose $0,75 \mathrm{~m}$ das extremidades de cada linha.

A aplicação do paclobutrazol nas mudas foi realizada aos $10 \mathrm{~d}$ após a semeadura, utilizando uma concentração de $42,5 \mathrm{mg} \mathrm{L}^{-1}$ e volume de $3,5 \mathrm{~mL}$ de solução por bandeja. A solução foi preparada a partir do produto comercial contendo $25 \%$ do ingrediente ativo. No momento da aplicação, as mudas apresentavamse com os folíolos do primeiro par de folhas medindo entre 3 a $5 \mathrm{~mm}$. A aplicação foi automatizada, realizada através de bicos pulverizadores dispostos em barras horizontais, que percorre todo o comprimento da estufa pulverizando as mudas com defensivos e nutrientes.

A semeadura foi realizada em bandejas de polipropileno com 450 células contendo substrato comercial, mantidas em viveiro com infraestrutura e suporte técnico. O manejo nutricional e o controle de doenças e insetos pragas foram realizados conforme a necessidade para o bom desenvolvimento das mudas. O transplante para o campo ocorreu aos 34 d após a semeadura e 24 d após a aplicação do regulador de crescimento.

Para as avaliações fitotécnicas foram verificadas as seguintes variáveis: a) comprimento da haste principal das plantas: médias de dez plantas/parcela, aos 07, 15, 30 e 45 d após o transplante, b) diâmetro médio do caule: médias dos diâmetros do caule de dez plantas/ parcela, aos 07, 15, 30 e 45 d após o transplante, c) teor de clorofila: média de cinco plantas/parcela, 15 e $45 \mathrm{~d}$ após o transplante, utilizando-se clorofilômetro digital (Falker $\left.{ }^{\circledR}\right)$, d) produção total, produção de frutos maduros, verdes e deteriorados: toneladas de frutos/ hectare, no momento da colheita, e) número médio de frutos: número total de frutos de todas as plantas úteis da parcela, em cada tratamento no momento da colheita, f) massa fresca média de fruto: média aritmética da massa fresca de todos os frutos colhidos na área útil da parcela, para cada tratamento na colheita, g) porcentagem de compressão e força máxima para rompimento da epiderme: média de três frutos/parcela, determinadas com o tomate pela região próxima ao pedúnculo, com auxílio de penetrômetro digital de placa, sendo os resultados expressos em porcentagem e em Newton (N), h) teor de sólidos solúveis (SS): média de 3 frutos/parcela, determinado por meio de refratômetro de bancada, na polpa triturada, sendo os valores expressos em ${ }^{\circ}$ Brix, i) acidez titulável (AT): média de 3 frutos/parcela, expressa em gramas de ácido por $25 \mathrm{~g}$ polpa, determinada por titulometria de acordo com as normas do Instituto Adolfo Lutz (1985), j) relação SS/AT, k) pH: por leitura em

Tabela 1. Composição química do solo, em área de pivô, na camada de $0 \mathrm{~cm}$ a $20 \mathrm{~cm}$. Anápolis/G0, 2013.

\begin{tabular}{|c|c|c|c|c|c|c|c|c|c|}
\hline P (Melich) & M. 0. & $\mathrm{pH} \mathrm{CaCl}{ }_{2}$ & K & $\mathrm{Ca}$ & $\mathrm{Mg}$ & $\mathrm{H}+\mathrm{Al}$ & SB & СTC & V \\
\hline $\mathrm{mg} \mathrm{dm}^{-3}$ & $\mathrm{~g} \mathrm{~kg}^{-1}$ & Un. & \multicolumn{6}{|c|}{ - } & $\%$ \\
\hline 53,30 & 16,90 & 4,99 & 0,15 & 2,90 & 1,10 & 3,20 & 4,15 & 7,35 & 56,48 \\
\hline
\end{tabular}

Análise de solo realizada por Cerrado Consultoria Agronômica, Palmeiras de Goiás, GO. 

Tabela 2. Comprimento da haste principal das plantas de tomate industrial em cm avaliadas aos 07, 15, 30 e 45 dias após o transplantio (DAT) em função do tratamento das mudas com paclobutrazol (PBZ) e espaçamento de plantio (ESP). Anápolis (G0), 2013.

\begin{tabular}{|c|c|c|c|c|}
\hline PBZ & 07 DAT (26/06/2013) & 15 DAT (11/07/2013) & 30 DAT (26/07/2013) & 45 DAT (10/082013) \\
\hline Com & $07,80 \mathrm{~b}$ & $13,53 b$ & $32,72 \mathrm{a}$ & $56,48 \mathrm{a}$ \\
\hline Sem & $11,30 \mathrm{a}$ & $14,75 \mathrm{a}$ & $30,76 b$ & 54,56 a \\
\hline$P$ & $<0,001 * *$ & $<0,0001 * *$ & $0,0048 * *$ & $0,0674 \mathrm{~ns}$ \\
\hline \multicolumn{5}{|c|}{$\mathrm{ESP}(\mathrm{m})$} \\
\hline 0,15 & 9,52 & 14,06 & 32,10 & 58,74 \\
\hline 0,20 & 9,26 & 14,03 & 33,52 & 56,30 \\
\hline 0,25 & 9,67 & 14,30 & 31,24 & 54,76 \\
\hline 0,30 & 10,15 & 14,86 & 30,31 & 54,24 \\
\hline 0,35 & 9,22 & 13,45 & 31,55 & 53,59 \\
\hline Regressão & ns & ns & ns & ns \\
\hline CV (\%) & 10,46 & 4,53 & 6,40 & 5,76 \\
\hline
\end{tabular}

Médias seguidas da mesma letra na coluna não diferem entre si pelo teste $F$; $\mathrm{A}^{*}(1 \%) \mathrm{e}^{* *}(5 \%)$ de probabilidade, ns: não significativo.

potenciômetro diretamente na polpa de tomate triturada, 1) teor de resíduos de paclobutrazol nos frutos: AOAC Official Method 2007.01

Os dados foram submetidos à análise de variância (teste F) e as médias do fator qualitativo (aplicação de paclobutrazol), comparadas pelo teste Tukey a 5\% de probabilidade. Enquanto que, para o fator quantitativo (espaçamentos), as médias foram submetidas a ajustes de regressão polinomial.

\section{RESULTADOS E DISCUSSÃO}

O crescimento das plantas de tomateiro diferenciouse estatisticamente entre as plantas que receberam ou não a aplicação do PBZ, até os $15 \mathrm{~d}$ após o transplantio (DAT), observando-se o menor desenvolvimento de plantas que receberam a aplicação do produto. Esta redução é devida à ação do PBZ como bloqueador da biossíntese de giberelina, ocasionando menor crescimento longitudinal das células, consequentemente no comprimento das plantas (Symons, 1989) No entanto, aos 30 DAT houve inversão na superioridade em altura, em que as plantas que receberam a aplicação de PBZ na fase de muda superaram as plantas não submetidas ao produto (Tab. 2), podendo-se inferir que o PBZ tem um residual efetivo nas plantas de tomate até os 15 DAT, após o qual é perdida a capacidade de supressão da síntese de giberelina, a qual segundo Taiz et al. (2017) é responsável pelo desenvolvimento do caule das plantas.
O resultado explicita a ausência de interferência no ciclo produtivo do tomateiro, uma vez que as plantas atingem igualdade do desenvolvimento 30 DAT, tornando a técnica exequível na produção das mudas.

Diferentemente do resultado obtido no presente estudo, foram relatadas reduções na estatura de plantas de tomateiro durante a fase pós transplantio, independente da concentração de PBZ empregada e dos híbridos utilizados (Silva e Faria Junior, 2011). Também se observou que a aplicação foliar de soluções aquosas a $0,2 \%$ de PBZ em mudas de tomateiro de $14 \mathrm{~d}$ retardou o crescimento das plantas, reduzindo em $35 \%$ a sua altura (Nascimento et al., 2003) e que a utilização de concentrações crescentes de PBZ resultam em diminuição na estatura do tomateiro, quando a aplicação é realizada na forma de aspersão sobre as mudas (Seleguini et al., 2016).

A aplicação do PBZ favoreceu o desenvolvimento da haste de plantas do tomateiro, em espessura, aos 15 e 30 DAT (Tab. 3), quando as plantas que receberam aplicação do regulador tiveram maior diâmetro. Hastes com maior calibre podem ser favoráveis à manutenção da planta e da produção durante o período à campo, atuando contra possíveis quebras propiciadas por fatores abióticos como vento e chuva. Em complemento, a sustentação dos frutos é favorecida, tendo em vista a força gerada pela massa dos tomates em desenvolvimento. 
Tabela 3. Diâmetro do colo da haste principal das plantas de tomate em $\mathrm{mm}$ avaliadas aos 07, 15, 30 e 45 dias após o transplantio (DAT), em função do tratamento das mudas com paclobutrazol (PBZ) e espaçamento de plantio (ESP). Anápolis (GO), 2013.

\begin{tabular}{|c|c|c|c|c|}
\hline PBZ & 07 DAT (26/06/2013) & 15 DAT (11/07/2013) & 30 DAT (26/07/2013) & 45 DAT (10/08/2013) \\
\hline Com & $1,90 \mathrm{a}$ & $4,16 a$ & $8,14 a$ & 10,68 a \\
\hline Sem & $1,95 \mathrm{a}$ & $3,54 b$ & $7,31 \mathrm{~b}$ & $10,30 \mathrm{a}$ \\
\hline$P$ & $0,1645 \mathrm{~ns}$ & $<0,0001 * *$ & $<0,0001^{* *}$ & $0,0868 \mathrm{~ns}$ \\
\hline \multicolumn{5}{|c|}{$\mathrm{ESP}(\mathrm{m})$} \\
\hline 0,15 & 1,91 & 3,98 & 7,66 & 10,10 \\
\hline 0,20 & 1,92 & 3,75 & 7,74 & 10,73 \\
\hline 0,25 & 1,94 & 3,98 & 7,91 & 10,90 \\
\hline 0,30 & 1,98 & 3,89 & 7,44 & 10,51 \\
\hline 0,35 & 1,87 & 3,69 & 7,88 & 10,22 \\
\hline Regressão & ns & $\mathrm{ns}$ & ns & ns \\
\hline CV (\%) & 11,07 & 8,87 & 6,52 & 6,26 \\
\hline
\end{tabular}

Médias seguidas da mesma letra na coluna não diferem entre si pelo teste F; a ${ }^{*}(1 \%) e^{* *}(5 \%)$ de probabilidade, ns: não significativo.

Aos 45 DAT os diâmetros se igualaram, evidenciando mais uma vez que o efeito do PBZ no crescimento não é prolongado, se limitando aos estádios iniciais do desenvolvimento da cultura. No entanto, o efeito do espaçamento entre plantas verificou-se que este não influenciou significativamente no crescimento das plantas em diâmetro nas quatro épocas avaliadas (Tab. 3).

Os diferentes espaçamentos não influenciaram no teor relativo de clorofila nas folhas, tão pouco houve interação entre as variáveis estudadas. No entanto, aos 15 DAT houve diferenças significativas, sendo que as plantas que receberam aplicação de PBZ apresentaram maior teor de clorofila. Aos 45 DAT, os teores de clorofila nas folhas se igualaram, não apresentando diferenças entre as plantas que receberam ou não aplicação de PBZ (Tab. 4).

A aplicação de PBZ favorece o aumento da atividade fotossintética e, consequentemente, o aumento dos teores de clorofila nas folhas (Berova e Zlatev, 2000). Esses resultados corroboram os resultados de outros estudos com tomateiros sob efeito da aplicação de PBZ, nos quais se verificaram aumentos significativos dos teores de clorofila foliar em plantas tratadas com o regulador (Davis, 1991; Berova e Zlatev, 2000),

Não houve interação significativa entre os fatores estudados, aplicação do regulador de crescimento paclobutrazol e densidade de plantas de tomate industrial, bem como não se verificou efeito do PBZ e da
Tabela 4. Teor de clorofila das folhas de plantas de tomate industrial em spad, avaliadas aos 15 e 45 dias após o transplantio (DAT), em função do tratamento das mudas com paclobutrazol (PBZ) e espaçamento de plantio (ESP). Anápolis (G0), 2013.

\begin{tabular}{|c|c|c|}
\hline \multicolumn{3}{|c|}{ Teor de clorofila nas folhas } \\
\hline PBZ & 15 DAT & 45 DAT \\
\hline Com & $51,83 \mathrm{a}$ & $52,85 \mathrm{a}$ \\
\hline Sem & $48,94 \mathrm{~b}$ & $52,99 \mathrm{a}$ \\
\hline$P$ & $9,1152^{* *}$ & $0,032 \mathrm{~ns}$ \\
\hline \multicolumn{3}{|c|}{ ESP (m) } \\
\hline 0,15 & 49,15 & 52,43 \\
\hline 0,20 & 52,10 & 51,57 \\
\hline 0,25 & 48,32 & 53,37 \\
\hline 0,30 & 50,97 & 53,87 \\
\hline 0,35 & 51,39 & 53,35 \\
\hline Regressão & $\mathrm{ns}$ & $\mathrm{ns}$ \\
\hline CV (\%) & 6,01 & 4,84 \\
\hline
\end{tabular}

Médias seguidas da mesma letra na coluna não diferem entre si pelo teste $F$; $a^{*}(1 \%)$ e ** $(5 \%)$ de probabilidade, ns: não significativo.

densidade de plantas nos componentes da produção do tomate industrial (Tab. 5).

No que se refere à produtividade, número de frutos por hectare e massa fresca de frutos, verificou-se que não houve efeito significativo da aplicação ou não do PBZ e também dos diferentes espaçamentos estudados (Tab. 5). Estes resultados são positivos, ao 


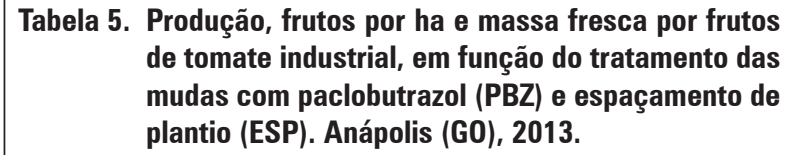

\begin{tabular}{|c|c|c|c|}
\hline PBZ & $\begin{array}{c}\text { Produção (t } \\
\left.\text { ha }^{-1}\right)\end{array}$ & $\begin{array}{c}\text { Frutos por ha } \\
(\times 1000)\end{array}$ & $\begin{array}{c}\text { Massa por } \\
\text { frutos }(\mathrm{g})\end{array}$ \\
\hline Com & $95,83 \mathrm{a}$ & $1.563 \mathrm{a}$ & $61,75 \mathrm{a}$ \\
\hline Sem & $99,60 \mathrm{a}$ & $1.632 \mathrm{a}$ & $61,44 \mathrm{a}$ \\
\hline$P$ & $0,3355 \mathrm{~ns}$ & $0,3824 \mathrm{~ns}$ & $0,8160 \mathrm{~ns}$ \\
\hline \multicolumn{4}{|c|}{$\mathrm{ESP}(\mathrm{m})$} \\
\hline 0,15 & 96,46 & 1.650 & 58,62 \\
\hline 0,20 & 91,34 & 1.471 & 62,29 \\
\hline 0,25 & 104,65 & 1.715 & 61,77 \\
\hline 0,30 & 98,53 & 1.623 & 61,12 \\
\hline 0,35 & 97,59 & 1.526 & 61,16 \\
\hline Regressão & $\mathrm{ns}$ & $\mathrm{ns}$ & $\mathrm{ns}$ \\
\hline CV (\%) & 12,44 & 15,40 & 6,65 \\
\hline
\end{tabular}

Médias seguidas da mesma letra na coluna não diferem entre si pelo teste $F_{\text {; }}$ $a^{*}(1 \%) e^{* *}(5 \%)$ de probabilidade, ns: não significativo.

passo que a manutenção da produtividade, mesmo em plantas que tiveram seu desenvolvimento afetado pela introdução do regulador, possibilita a prática de manejos mais adequados a campo. Plantas menores tentem a apresentar menor probabilidade de formação de microclima que, por sua vez, pode propiciar a proliferação de agentes patogênicos (Peil et al., 2014).

Quanto ao espaçamento, verificou-se a inexistência de efeito significativo sobre componentes de produção do tomateiro. A média de produção alcançada nos diferentes espaçamentos foi de $97,7 \mathrm{t} \mathrm{ha}^{-1}$, considerada acima das médias de produção nacional. Resultados semelhantes foram encontrados por Peil et al. (2014), que trabalharam com dois genótipos diferentes de tomate cereja em diferentes densidades de plantio e concluíram que quanto ao número de frutos por planta não houve efeito da densidade para 'Cereja Vermelho' e 'Flavor Top'. Em contrapartida, o aumento da densidade de plantio causou redução linear na massa fresca média dos frutos de 'Cereja Vermelho'. Para ambos os genótipos, o aumento da densidade de plantio diminui de forma linear a produção de frutos por planta, indicando possível competição por recursos.

$\mathrm{Na}$ produção de frutos classificados conforme sua maturação não foi observada diferença entre as plantas que receberam ou não a aplicação de PBZ, entre os diferentes espaçamentos estudados e entre a interação dos fatores. Observou-se uma média de 62,04; 36,68 e 4,62 t ha $\mathrm{t}^{-1}$ de frutos maduros, verdes e deteriorados, respectivamente. Esses resultados divergem de outro estudo, o qual demonstra que o adensamento do tomateiro pode promover o aumento na produtividade, sem comprometer a qualidade dos frutos e o controle fitossanitário (Wamser et al., 2012).

Da mesma forma, não houve significância para o número e a massa média de frutos maduros ou verdes. Verificou-se que, em média, do total de frutos colhidos, 852.250 foram frutos maduros e 745.250 frutos verdes, dos quais se obteve uma massa média por fruto de 73,02 e 49,95 g, respectivamente.

Resultados semelhantes foram encontrados por Seleguini et al. (2016), quanto ao número de frutos por área e massa de matéria fresca de fruto, onde verificou que não houve efeito significativo em diferentes concentrações de PBZ aplicado na cultura do tomate. Segundo esses mesmos autores, embora o aumento das concentrações de PBZ não tenha favorecido a produtividade, esta também não foi afetada negativamente pelas modificações na arquitetura da planta para um formato mais compacto. Assim, a aplicação do PBZ pode favorecer o aumento da densidade de plantas, evitando o excesso da sobreposição de folhas.

Quanto aos parâmetros químicos analisados, sólidos solúveis, pH, acidez titulável e relação SS/AT, estes não se diferenciaram entre as plantas que receberam ou não a aplicação do PBZ e entre os diferentes espaçamentos de plantio estudados. Os valores dos parâmetros químicos analisados obtidos no estudo não foram prejudicados, e estão dentro dos valores desejados pelas indústrias de processamento industrial de tomate. As médias obtidas foram de $3,93^{\circ}$ Brix para o teor de sólidos solúveis, pH de 4,39, acidez titulável de $0,35 \%$ e uma relação SS/AT de 11,35.

Para a firmeza de frutos, verificou-se que o tratamento das plantas com PBZ, o plantio em diferentes espaçamentos e a interação entre estas variáveis, não afeta a característica. Verificou-se que, em média os frutos suportaram uma compressão de 33,33\% antes de ocorrer o rompimento da epiderme, que culminou em uma força máxima de 76,27 N no momento do rompimento. A produção de frutos firmes melhora consideravelmente as condições pós-colheitas, transporte e comercialização, diminuindo a susceptibilidade aos danos mecânicos e a deterioração pela ação de microrganismos (Villa Boas et al., 2000). 
As determinações de resíduos de agrotóxicos em alimentos para fins de verificação de grau de contaminação são escassas. Neste sentido, verificou-se a inexistência de resíduos do regulador de crescimento paclobutrazol nas amostras de tomate industrial. Berova e Zlatev (2000) também afirmaram que não encontraram quaisquer resíduos do regulador PBZ nos frutos de tomate, sendo, portanto, considerado do ponto de vista fitossanitário, inofensivo à saúde humana.

\section{CONCLUSÕES}

A aplicação de paclobutrazol nas mudas no viveiro não influencia negativamente no desenvolvimento vegetativo das plantas, nos componentes de produção e qualidade do tomate industrial.

Diante dos resultados deste trabalho, no qual os diferentes estandes não influenciaram no desenvolvimento vegetativo, na produção total e qualidade do tomate industrial, pode-se analisar a utilização de maiores espaçamentos entre as plantas, utilizando uma menor quantidade de mudas por área, sem afetar a produção total.

A aplicação do regulador de crescimento paclobutrazol nas mudas não deixa resíduos nos frutos de tomate industrial.

\section{REFERÊNCIAS BIBLIOGRÁFICAS}

Adpawar, R.M., P.B. Kale, V.S. Kale, N.S. Guputa e S.G. Bharad. 2000. Effect of spacing and staking on growth, yield and quality of tomato var. Dhanshree. Ann. Plant Physiol. 14(1), 26-31.

Berova, M. e Z. Zlatev. 2000. Physiological response and yield of paclobutrazol treated tomato plants (Lycopersicon esculentum Mill.). J. Plant Growth Regul. 30(2), 117-123. Doi: 10.1023/A:1006300326975

Carvalho, L.A. e J. Tessarioli Neto. 2005. Produtividade de tomate em ambiente protegido, em função do espaçamento e número de ramos por planta. Hort. Bras. 23(4), 986- 989. Doi: 10.1590/S0102-05362005000400025

Embrapa Hortaliças. 2003. Cultivo de tomate para industrialização. Em: Sistema de Produção, http://sistemasdeproducao.cnptia.embrapa.br/FontesHTML/ Tomate/TomateIndustrial/cultivares.htm; consulta: dezembro de 2016.

Rabelo, M. 2014. Faeg participa do Congresso Brasileiro de Tomate Industrial, Michelle Rabelo, 27 nov. 2014. Em:
Federação da Agricultura e Pecuária de Goiás, http:// sistemafaeg.com.br/noticias/10796-faeg-participa-docongresso-brasileiro-de-tomate-industrial; consulta: dezembro de 2016.

Fery, R.L. e J. Janick. 1970. Effect of planting pattern and population pressure on the yield response of tomato. HortScience 5, 443-444.

Fontes, P.C.R. e D.J.H. Silva. 2005. Cultura do tomate. pp. 457-475. In: Rezende, P.C. (ed.). Olericultura: teoria e prática. Universidade Federal de Viçosa, Viçosa, Brasil.

Instituto Adolfo Lutz. 1985. Normas analíticas do Instituto Adolfo Lutz: métodos químicos e físicos para análises de alimentos. $3^{\text {a }}$ ed. IMESP, São Paulo, Brasil.

Nichols, M.A. 1987. Plant spacing: key to greater process vegetable crop productivity. Acta Hortic. 220, 223-228.

Nimer, E. 1979. Climatologia do Brasil. IBGE, Rio de Janeiro, Brasil.

Nunhems Tech Sheet. N901 Tomate híbrido - Processamento. Em: Nunhems, http://nunhems.com.br/www/ NunhemsInternet.nsf/CropData/BR_PT_TOP/\$file/ BR_TOP_N901.pdf; consulta: julho de 2014.

Peil, R.M.N., A.R. Albuquerque Neto e C.V. Rombaldi. 2014. Densidade de plantio e genótipos de tomateiro cereja em sistema fechado de cultivo em substrato. Hort. Bras. 32(2), 234-240. Doi: 10.1590/ S0102-05362014000200021

Schwarz, K., J.T.V. Resende, A.P. Preczenhak, J.T. Paula e D.M. Dias. 2013. Desempenho agronômico e qualidade físico-química de híbridos de tomateiro em cultivo rasteiro. Hort. Bras. 31(3), 410-418. Doi: 10.1590/ S0102-05362013000300011

Seleguini, A., S. Seno e G.B. Zizas. 2002. Influência do espaçamento entre plantas e número de cachos por plantas na cultura do tomateiro, em condições de ambiente protegido. Hort. Bras. 20(2), 25-28.

Seleguini, A., S. Seno e M.J.A. Faria Júnior. 2006. Espaçamento entre plantas e número de rácimos para tomateiro em ambiente protegido. Acta Sci. Agron. 28(3), 359-363.

Seleguini, A, E.P. Vendruscolo, L.F.C. Campos e M.J.A. Faria Júnior. 2016. Efeito do paclobutrazol sobre o crescimento de plantas e produção de tomate (Solanum lycopersicum L.) em ambiente protegido. Sci. Agropecu. 7(4), 355-363. Doi: 10.17268/sci. agropecu.2016.04.04

Silva, K.S. e M.J.A. Faria Junior. 2011. Uso de paclobutrazol como estratégia para redução do porte e da brotação lateral de plantas de tomateiro. Ciênc. Agrotec. 35(3), 539-546. Doi: 10.1590/S1413-70542011005000004

Symons, P.R.R. 1989. Paclobutrazol: it's application and effect on aspects of plant morphology, anatomy, biochemistry and physiology. Department of 
Horticultural Science; University of Natal, Pietermaritzburg, KZN.

Taiz, L., E. Zeiger, I.M. Moller e A. Murphy. 2017. Fisiologia e desenvolvimento vegetal. $6^{\mathrm{a}}$ ed. Artmed, Porto Alegre, Brasil.
Wamser, A.F., S. Mueller, A. Suzuki, W.F. Becker e J.P. Santos. 2012. Produtividade de híbridos de tomate submetidos ao cultivo superadensado. Hort. Bras. 30(1), 168-174. Doi: 10.1590/S0102-05362012000100028 